\title{
Ammonia Nitrogen Speciation Analysis in Aquatic Environments
}

\author{
Xia LIU \\ Tianjin Key Laboratory of Marine Resources and Chemistry \\ Tianjin University of Science and Technology \\ Tianjin, PRC China \\ Yafei GUO \\ Tianjin Key Laboratory of Marine Resources and Chemistry \\ Tianjin University of Science and Technology \\ Tianjin, PRC China \\ College of Chemistry and Materials Science \\ Northwest University \\ Xi'an, PRC China
}

\author{
Qing XU \\ Tianjin Key Laboratory of Marine Resources and Chemistry \\ Tianjin University of Science and Technology \\ Tianjin, PRC China \\ Xiaoping YU \\ Tianjin Key Laboratory of Marine Resources and Chemistry \\ Tianjin University of Science and Technology \\ Tianjin, PRC China \\ College of Chemistry and Materials Science \\ Northwest University \\ Xi'an, PRC China \\ e-mail: yuxiaoping@tust.edu.cn
}

\author{
Tianlong DENG \\ Tianjin Key Laboratory of Marine Resources and Chemistry \\ Tianjin University of Science and Technology \\ Tianjin, PRC China
}

\begin{abstract}
The accurate measurement of different species of ammonia nitrogen is essential to understanding of the self purification and pollution status of water system as well as revealing the aquatic ecological environment. In the paper, the analytical methods for ammonia nitrogen species in aquatic environments on spectrophotometry, distillation-titration method, chromatographic analysis, gas phase molecular absorption spectrometry, electrode method, flow-injection analysis were systematically summarized. The principle of the mentioned methods, scope of applications and the different influence factors were discussed, and the new trend in the future was also pointed out.
\end{abstract}

Keywords-ammonia nitrogen; analysis; pretreatment; aquatic environmental sample

\section{INTRODUCTION}

The species of ammonia nitrogen in aquatic environment are mainly in free ammonia $\left(\mathrm{NH}_{3}\right)$ and ammonium ion $\left(\mathrm{NH}_{4}{ }^{+}\right)$. The concentration of ammonia nitrogen in drinking water is strictly specified in most European countries [1]. Nessler's reagent spectrophotometry (HJ 535-2009) and salicylic acid spectrophotometry (HJ 536-2009) are recommended for the determination of ammonia nitrogen [2]. With the improvement of analytical requirements, some new technologies are correspondently developed and reviewed in this paper.

\section{SPECTROPHOTOMETRY}

\section{A. Nessler's Reagent Spectrophotometry}

Nessler's reagent spectrophotometry is widely used in environmental monitoring. Wu et al. [3] determined the ammonia nitrogen in water samples by double wavelength spectrophotometry. The interferences of residual turbidity and baseline drifting of instrument would be corrected. $\mathrm{Ca} 2+$, $\mathrm{Mg} 2+$ and other metal ions are easy to react with $\mathrm{OH}-$ or Iions in the reagent in case to lead the effects of analysis by water turbidity and color. The stability of complex is affected by the contents of $\mathrm{OH}$ - and ammonia nitrogen, and sulfide, aldehydes, so corresponding pretreatments is necessary. In addition, it is harmful to the environment and human health because of the use of toxic mercury salt.

\section{B. .Indophenol Blue Spectrophotometric Method}

Indophenol blue spectrophotometry is one of the recommended methods for marine monitoring in China. Solórzano et al. [4] shows that the color of indophenol - blue may become yellow or green, which will make the result unreliable, and this phenomenon was also proved in Zhou's study [5].

It is worth noting that the production of phenol and ochlorophenol used in the method are harmful, so it is usually replaced by salicylic acid. Moreover, the reaction time of indophenol blue spectrophotometry is long and its accuracy is not very high if the method is used in the determination of ammonia nitrogen in heavily polluted seawater and aquaculture water. 


\section{Salicylic Acid Spectrophotometry}

Salicylic acid spectrophotometry is improved based on the indophenol blue spectrophotometry and the replacement of phenol by salicylate sodium can effectively avoid the emission of volatile toxic o-chlorophenol. Le et al. [6] determined the concentration of ammonia nitrogen in aqueous solution with different salinity by salicylic acid spectrophotometry and indophenol blue spectrophotometry respectively. The result showed that the average concentration and the precision with salicylic acid spectrophotometry are higher than that of indophenol blue spectrophotometry.

\section{Pobromite Oxidation Spectrophotometry}

Hypobromite oxidation spectrophotometry is one of the recommended methods for marine monitoring. Although the hypobromite oxidation spectrophotometry has the advantages of high oxidation rate, simple operation and high sensitivity, it is remarkable that the result may be higher than the really value if there is amino - acid in the sample. And if the existences either organism or reducing substance in the sample, the oxidizing agent will first react with the lower oxidation - reduction potential substance, so that ammonia can not be completely oxidized. This will lead to low absorbance and affect the accuracy of determination. Therefore, this method can not be applied to the determination of ammonia nitrogen in polluted water samples.

\section{FLUORESCENCE METHOD}

Wang et al. [7] determined ammonia nitrogen in seawater, founding that sodium sulfite had a good sensitizing effect and stabilization effect for the system. Ionic strength slightly influences the fluorescence intensity of the product. This method needs no pretreatment, establishing the foundation of field detection. It is noteworthy that background interference of o-phthalaldehyde and organic matter and matrix interference are serious, and especially the presence of salinity, amines, amino acids, algae, and particulate matter would be interfered the determination. Therefore, this method is suitable for the determination in the sample with poor nutrition, rather than coastal eutrophication environment.

\section{Distillation Titration Method}

When ammonia nitrogen was determined by distillation titration method, $\mathrm{pH}$ need to be regulated to $6.0 \sim 7.4$ with $\mathrm{NaOH}$ or $\mathrm{H} 2 \mathrm{SO} 4$, and then regulated to slightly alkaline by adding light magnesium oxide if the $\mathrm{pH}$ is acidic or basic. Qi et al. [8] improved distillation titration method for the determination in wastewater. The amount of boric acid absorption liquid and distillation time were reduced, which could improve the analytical efficiency. Due to distillation titration method has the advantages of simple operation, and no use of toxic reagents, it is suitable for the determination of high concentration ammonia in domestic sewage and industrial wastewater. Due to the time costs, it is not appropriate for the rapid determination of batch samples.

\section{ION CHROMATOGRAPHY}

Ion chromatography needs no derivative treatment, and can separate and determine alkali, alkali - earth metal ions and ammonia on line at the same time [9]. Chromatographic analysis has good separation ability and high sensitivity, which is suitable for separating and determining samples with complicated components [10]. Chromatography simplifies the determination process and reduces the consumption of the toxic reagent. However, high concentration of sodium ion will seriously effect the determination because it is similar with ammonia in the selectivity to stationary phase. The high ionic strength of the salt degree in water will cause damage to the column. In addition, the detection cost is relatively high. Lin et al. [11] combined the improved purge and trap system with chromatography to determine ammonia nitrogen in concentrated brine. The method significantly improves the accuracy of the determination when compared with the results of Wang [12].

\section{Gas Phase Molecular AbSORPTION SPECTROMETRY}

This method has the advantages of fast analysis speed and a wide linear, and sample can be injected directly without complex chemical separation processes. Zhou et al. [13] improved the pretreatment condition of gas - phase molecular absorption method. Compared with the standard method, the sensitivity was increased by more than $60 \%$, and the recovery could be up to $97.5 \% \sim 104.4 \%$. The improved method can also shorten the processing time from $30 \mathrm{~min}$ to 2 min.

The influence of temperature for the sensitivity is great in the process of determination by gas - phase molecular absorption spectroscopy. In addition, the long oxidation time and high dependence on instrument in a high detection cost, so its application has been limited.

\section{EleCtRode Method}

Ion selective electrode method is not affected by the color and turbidity of samples, and it can be used directly when the content of ammonia nitrogen is excess the measuring range of spectrophotometry, avoiding the error caused by dilution. The upper limit of the determination by ion selective electrode can be up to $17 \mathrm{~g} / \mathrm{L}$ according to Zhou [5]. Ammonia sensitive electrode method has been widely used in water quality automatic detection station. However, sodium and potassium will produce serious interference on the determination by ammonia sensitive electrode method. The determined value of ammonia sensitive electrode method was $2.7 \sim 8$ times higher than that of salicylic acid spectrophotometry because of the presence of potassium and sodium [5].

\section{Flow Injection Analysis Method}

Flow injection analysis is suitable for industrialized and automated online analysis. He et al. [14] determined ammonia nitrogen in sewage by this method, and eliminated the miscellaneous work of pretreatment. Flow injection 
analysis is an automatic analysis system, which is easy to realize the link between the field and near the laboratory. However, if the water is cloudy or has granular material, it is easy to plug the capillary, so it needs membrane filtration before analysis.

\section{REAGENT KIT ANALYSIS}

Reagent kit has been well applied in the field of water quality monitoring. At present, the reagent kit is mainly Nessler's reagent kit, phenolate kits and salicylic acid hypochlorite kit. Nessler's reagent kit was developed early and its preparation technique is relatively mature. Presently, it has been commercialized. However, a highly toxic mercury salt is used in the preparation process, so its application has been limited. Wang et al. [15] developed phenolate kits based on indophenol blue spectrophotometry, which could overcome the problem of mercury pollution. $\mathrm{Wu}$ et al. [16] developed solid powder reagent kit. The reagent kit can be stored for more than 3 years in dark condition and sodium hydroxide was replaced with sodium carbonate - sodium borate buffer reagent, which solved the problem of deliquescence of sodium hydroxide [17].

\section{COnClusions And Prospects}

Generally speaking, spectrophotometry is still a common method. New trend in the development of analytical methods is to develop on - line real - time monitoring and automation technology with the advantages of low reagent consumption, environmental friendly and simple and fast. Chromatography with the characters of simultaneous determination of multiple-elements has been applied popularly at present years. Flow injection analysis and gas continuous flow analysis are suitable for the treatment of large volume samples. Reagent kit technology for rapid determination is an important development direction of technological innovation. It can be foreseen that the method will be widely used in monitoring in the near future.

\section{ACKNOWLEDGEMENTS}

Financial supports from the National Natural Science Foundation of China (U1407113, U160710183 and U160710097), the Application Foundation and Advanced Technology Program of Tianjin (15JCQNJC08300), the Higher School Science and Technology Development Fund of Tianjin (20140511) and the Chinese Postdoctoral Science Foundation (2016M592827 and 2016M592828) are acknowledged.

\section{REFERENCES}

[1] L.Y. Yu, H.H. Zhao, X.S. Zhang, Determination of ammonia nitrogen in water, J. West Leather 32, 27-33 (2010) (in Chinese).
[2] H. Wang, A. Li, J.W. Yang, Optimized conditions of Nessler's reagent spectrophotometry for ammonia nitrogen determination in seawater, J. Journal of Liaoning Normal University (Natural Science Edition) 36, 110-114 (2013) (in Chinese).

[3] H.L. Wu, S.B. Hu, X.S. Chai, et al., Rapid detection of ammonia nitrogen in water with dual - wavelength spectroscopy, $J$. Spectroscopy and Spectral Analysis 36, 1396-1399 (2016) (in Chinese).

[4] L. Solórzano, Determination of ammonia in natural waters by the phenol hypochlorite method, J. Limnology and Oceanography 14, 799-801 (1969).

[5] L. Zhou, C.E. Boyd, Comparison of Nessler, phenate, salicylate and ion selective electrode procedures for determination of total ammonia nitrogen in aquaculture, J. Aquaculture 450, 187-193 (2016).

[6] P.T.T. Le, C.E. Boyd, Comparison of phenate and salicylate methods for determination of total ammonia nitrogen in freshwater and saline water, J. Journal of the World Aquaculture Society 43, 885-889 (2012).

[7] N. Wang, C. Wang, Q. Ha, et al., Fluorometric method for the determination of ammonium in seawater, J. Ocean Technology 29, 20-22 (2010) (in Chinese).

[8] F.P. Qi, J.H. Dang, Improvement of the determination of ammonia nitrogen in wastewater by distillation and titration method, $J$. Chemical Engineering and Equipment, 185-187 (2013) (in Chinese).

[9] R. Michalski, Applications of ion chromatography for the determination of inorganic cations, J. Analytical Chemistry 39, 230250 (2009).

[10] G.S. Wang, Changes of ammonia - nitrogen in surface water and quality controls in examination, J. Shanxi Chemical Industry 22, 3437 (2002) (in Chinese).

[11] T.Y. Lin, Y.T. Pan, H.Y. Lee, et al., Markedly enhanced purge - and trap performance and efficiency for the determination of ammonium ion in high - salinity water samples, J. Journal of the Chinese Chemical Society 59, 718-726 (2012).

[12] P.Y. Wang, J.Y. Wu, H.J. Chen, et al., Purge - and - trap ion chromatography for the determination of trace ammonium ion in high - salinity water samples, J. Journal of Chromatography A 1188, 69-74 (2008).

[13] K. Zhou, Y.Y. Liu, Y.P. Zhen, An improved method on rapid determination of ammonia nitrogen in water by gas phase molecular absorption spectrometry, J. Environmental Science and Technology 36, 149-222 (2013) (in Chinese)

[14] Q.Q. He, Y.Y. Dou, R. Xu et al., Determination of ammonia nitrogen in wastewater by continuous flow analysis with online distillation and unattended system, J. Environmental Monitoring and Forewarning $\mathbf{8}$, 18-20 (2016) (in Chinese).

[15] Z.H. Wang, J.W. Li, L. Liu, et al., Development and application of new - type eco - friendly kit for rapid test of ammonia nitrogen in water, J. Chinese Journal of Health Laboratory Technology 24, 21462148 (2014) (in Chinese).

[16] D. Wu, S.R. Zhou, Y. Liu, Study on rapid detection method of ammonia nitrogen in aquatic environment, J. Chinese Journal of Analysis Laboratory 34, 429-432 (2015) (in Chinese).

[17] J.H. Deng, Q.P. Wu, F.Y. Liao, et al., Rapid detection of ammonia nitrogen in environmental water, J. Environmental Monitoring Management and Technology 19, 33-34 (2007) (in Chinese). 